\title{
¿Creare est unire? Esbozo de la metafísica de la unión de Teilhard de Chardin
}

\section{(Creare est unire? An outline of Teilhard de Chardin's metaphysics of union)}

\section{RICARD CASADESÚS}

Facultat de Filosofia, Universitat Ramon Llull, Barcelona, España ricard.casadesus@gmail.com

Resumen. Como hilo conductor subyacente en toda su obra, Teilhard de Chardin desarrolla la relación entre espíritu y materia. La materia (multiplicidad) y el espíritu (unidad) están relacionados así: la centricidad (unidad) depende de la complejidad (multiplicidad). Para Teilhard, no hay en el universo más que espíritu en estados o grados diversos de organización o de pluralidad. Si se la define como una cosa sin rastro de conciencia, la materia no existe. El Espíritu surge novedosamente por síntesis sucesivas, por lo que él llama ley de centro-complejidad. A partir de la centro-complejidad, presentamos aquí cómo Teilhard distingue tres zonas en el universo: la pre-viviente, la viviente y la del pensamiento (noosfera); y a la vez, exponemos cómo basa su filosofía de la creación en un monismo no materialista y en una especie de pansiquismo, para evitar un dualismo radical entre espíritu y materia, que le permite explicar en qué sentido el espíritu surge desde la unión de la materia. Basándose en su espiritualidad, Teilhard quiere integrar fe y ciencia para hacer una interpretación cristiana del mundo.

Palabras clave: metafísica de la unión; creación; centricidad; complejidad; conciencia.

Abstract. As underlying leitmotiv throughout all his work, Teilhard de Chardin develops the relationship between spirit and matter. Matter (multiplicity) and spirit (unity) are 
related as follows: centricity (unity) depends on the complexity (multiplicity). Nothing in the universe exists but spirit in different states or degrees of organization or plurality for Teilhard. If it is defined as a thing without a trace of consciousness, matter does not exist. The Spirit comes innovatively by successive synthesis, by what he calls law of central-complexity. From the central-complexity, we present here how Teilhard identifies three areas in the universe: the pre-living, the living and thinking (noosphere); and yet, we expose how he bases its philosophy of creation in a non-materialistic monism and a kind of panpsychism, to avoid a radical dualism between spirit and matter, which enables him to explain in what sense the spirit emerges from the union of matter. Hence based on its spirituality, Teilhard wants to integrate Science and Faith for a Christian worldview.

Key words: metaphysics of union; creation; centricity; complexity; conscience.

El pensamiento de Marie-Joseph Pierre Teilhard de Chardin (1881-1955) es marcadamente inmanentista, evolucionista y emergentista. Teilhard de Chardin parte de la convicción de que vivimos en un universo que cambia de forma irreversible. Esta cosmovisión parte de la intuición de que todo lo que es material, humano, inmanente apunta, crece, evoluciona hacia lo espiritual, lo ultrahumano, lo sobrenatural, lo metafísico, lo teológico, lo divino...

Así, en su Weltanschauung, Teilhard de Chardin distingue tres niveles de percepción: física o fenomenología, metafísica o hiper-física y mística. Pero, el objeto de percepción siempre es la realidad entera. En el contexto teilhardiano, física significa un tipo de fenomenología, una fenomenología del cosmos, de la vida y, particularmente, de la humanidad y su historia. Por tanto, las cuestiones relativas al futuro de la humanidad y del universo son parte de la física de Teilhard. La metafísica o hiper-física interpreta el proceso de evolución como un efecto de unificación, como un proceso de creación y un proceso de cristificación. Así, el concepto teilhardiano de evolución no se restringe a la evolución biológica, sino que incluye la historia del universo y la de la humanidad. En este sentido, el concepto de unión es crucial para una creación por evolución dentro de la concepción teilhardiana del mundo. 


\section{Influencias fundamentales en el pensamiento de Teilhard de Chardin}

Las ideas de Teilhard, fruto de sus intuiciones, no han surgido de golpe en su pensamiento, sino que se han ido desarrollando a partir de varias influencias recibidas. Los filósofos que más influyeron en el pensamiento de Teilhard fueron Henri Bergson (1859-1941), Maurice Blondel (1861-1949) y Wilhelm Dilthey (1833-1911), con su concepción de las ciencias del espíritu.

La obra de Bergson L'évolution créatrice (Bergson 1907) despertó a Teilhard del sueño dogmático y señaló una dirección de la evolución hacia el hombre. Parece que Teilhard leyó esta obra durante su etapa de estudios de teología en Hastings (Inglaterra) entre 1908 y 1912. Así, Bergson le revela, por un lado, la diferencia entre tiempo y duración y, de otro lado, el élan vital, este flujo sutil que empuja hacia delante y hacia arriba. Al principio, Teilhard quedó admirado por esta obra de Bergson (y por toda su obra, pues, en la etapa de la guerra Teilhard leyó todas sus obras (Barthélémy-Madaule 1963, 287)), hasta lo llamaba "el gran Bergson" (Teilhard de Chardin 1961, 76: "Ainsi l'a très bien vue le grand Bergson") en una carta a su prima Marguerite Teilhard-Chambon (escritora francesa que usaba el pseudónimo de Claude Aragonnès), fechada el 5-6 de agosto de 1915. De hecho, él mismo dice que L'évolution créatrice de Bergson fue para él “un fuego que ya había devorado mi corazón y mi espíritu" (Teilhard de Chardin, Euvres, XIII, 33).

Bergson se opone a la concepción mecanicista del neodarwinismo y se acerca a las ideas de la ortogénesis ${ }^{1}$ (evolución lineal no adaptativa con acentuación de un carácter), por la existencia de un élan vital que empuja la vida a avanzar en algunos de los caracteres morfológicos. Pero, Teilhard ataca la idea del élan vital bergsoniano por falta de finalidad: "Por el único hecho de reconocer al Devenir universal la figura de una convergencia, queda eliminada la idea bergsoniana de un impulso vital sin finalidad" (Teilhard de Chardin 1965, 181). También se distancia de Bergson en otros aspectos de la evolución, como veremos más adelante.

El término “ortogénesis” fue propuesto por Gustav H. T. Eimer en 1888 para designar la evolución progresiva que tiene lugar en un sentido determinado.

Scientia $t$ Fides 3(2)/2015 
Por otro lado, Teilhard se familiarizó también con Blondel. De él, recibe la influencia del valor de la acción y de la noción del pancristismo. Blondel sostiene que el universo no es sino que se va haciendo, que llega a ser (in fieri) a través de un proceso en tres fases -cósmica, psíquica y espiritual-, en ascenso creciente hacia lo más perfecto, cuya culminación es el Cristo Total, que es la plena inhabitación de Cristo en los cristianos (pancristismo).

Este inmanentismo, en el sentido de la inserción natural de Dios en el mundo, que defiende Blondel, Teilhard la asume como propia, con la satisfacción de ver confirmada su hipótesis en el plano filosófico. Además, Teilhard sigue a Blondel también al dar el salto de la ortogénesis a la trascendencia.

De este modo, Teilhard se sitúa en el marco de las concepciones neolamarckistas, heredadas de la filosofía de la biología francesa, cuyo evolucionismo contenía un fuerte elemento del lamarckismo, debido a que los excesos del neodarwinismo (o ultradarwinismo) de Weismann hicieron necesaria una alternativa a la teoría de la selección natural. No es extraño que Teilhard optara, principalmente, por el neolamarckismo, ya que éste va muy unido a las ideas de ortogénesis que defendía Teilhard (Sequeiros 2008 , 28). Contrariamente, el darwinismo, aunque admite un incremento en el número de formas en la evolución, nunca admitió la direccionabilidad de la misma. De ahí, que la comprensión teilhardiana de la evolución difiera del darwinismo.

Por otro lado, respecto a su influencia posterior, quizá uno de los críticos más severos de Teilhard ha sido Jacques Monod, biólogo molecular y premio Nobel de fisiología y medicina en 1965. Para Monod, el principio de objetividad como inmanentismo, es decir, el no ser capaz de concebir nada en la naturaleza en términos de un proyecto, obliga a decir que ni el destino del universo ni su cometido están escritos en ningún lado.

En cambio, la crítica de Monod contrasta con la posición del genetista Theodosius Dobzhansky con respecto a las obras de Teilhard. Para Dobzhansky, Teilhard de Chardin no quería construir su cosmovisión basada solamente en la ciencia, sino que la obra de Teilhard es ciencia, metafísica, teología y hasta poética (Núñez de Castro 2008a, 107-108). 


\section{La novedad de la metafísica teilhardiana: creación por unión}

La intención de Teilhard, en principio, no era de negar la metafísica escolástica ni, por supuesto, los dogmas teológicos que se sustentaban en ella para su formulación racional. Su preocupación no fue puramente científica, sino que estaba interesado en hacer compatibles la teología y la ciencia de su tiempo, para lo cual fue necesario construir una nueva metafísica que sirviera de puente, que él llamó «de la unión» y que partía del plus esse (ser más), frente a la metafísica greco-escolástica del esse (ser). En todo caso, en Teilhard hay una verdadera metafísica, pero no deductiva desde arriba, sino desde abajo, como la describe él mismo en una carta a Bruno de Solages:

Como sabe usted, yo no me siento cómodo en las Metafísicas (entendidas como un proceso de comprensión del mundo per descensum, deductivamente). Sólo me siento cómodo en las hiperfísicas, procediendo per ascensum (Teilhard de Chardin 1974, 411).

Por otro lado, Teilhard sitúa el punto de partida de toda su obra en la idea de que el universo está sujeto a un devenir. Esto es ya un claro alejamiento de Teilhard respecto a la metafísica tradicional, que acostumbraba partir del ser. Ahora bien, este devenir no carece de sentido, sino que manifiesta un sentido absoluto, en tanto que se dirige hacia el espíritu; esto es, a la espiritualización progresiva de las conciencias. De este modo, lo que pretende Teilhard es explicar, precisamente, la génesis del espíritu.

En su Diario (Teilhard de Chardin, Euvres, XII, 43), Teilhard reflexiona profundamente sobre la cuestión de la materia y de su naturaleza cuasi espiritual; cuestión decisiva para evitar el dualismo espiritualista y el reduccionismo materialista, y desarrollar un monismo no-materialista. De hecho, Teilhard escribía en las trincheras durante la I ${ }^{\text {a }}$ Guerra Mundial: "Dejando al material inferior el único atributo de la Multiplicidad, es preciso reconocer que la verdadera Materia... es el Espíritu" (Teilhard de Chardin 1965, 190). 
Según Teilhard, el espíritu surge por la unión cada vez más íntima (centramiento) de elementos variados que, al sintetizarse progresivamente, van dando lugar a un incremento de ser y a la aparición de la conciencia (Plus esse = plus, et a pluribus, uniri; ser más = estar más unido, y a partir de varios elementos). Por tanto, podemos decir que la complejidad material es directamente proporcional al aumento de profundidad psíquica o espiritual. Esto es lo que le lleva a afirmar que en el origen había una especie de multiplicidad pura, a partir de la cual se lleva a cabo el acto creador primero, que continuará luego a través de la unión de sucesivos elementos cada vez más íntimamente sintetizados. Esta multiplicidad pura sería la nada primigenia, la nada sin ninguna especie de existencia; así, la nada es, para Teilhard, la base de la unión. Así que la unión es creadora; es decir, a partir de la unión surge algo completamente nuevo.

En una carta a su prima Marguerite Teilhard-Chambon con fecha del 8 de octubre de 1917, Teilhard expone su intención de escribir un ensayo de síntesis filosófica bajo el título L’union créatrice (Teilhard de Chardin 1961, 272).

La metafísica que expone Teilhard en este ensayo tiene su base en la definición esse = uniri, que se revela como la ley del progreso del ser. Por eso, Teilhard también dice que crescere = uniri, pues esa ley posee un valor práctico de crecimiento (Teilhard de Chardin 1965, 172). Así lo expone Teilhard en el primer capítulo de L'union créatrice (UC) (Teilhard de Chardin, Euvres, XII, 193-224): “A medida que la unión entre los elementos más variados ha ido haciéndose más íntima (y cuanto más la multitud ha sido superada), más ha aparecido el ser como perfecto y consciente” (Teilhard de Chardin 1965, 177). Tanto la creación como este crecimiento del ser por unión son transversales en toda la obra de Teilhard.

Así, en la obra Comment je vois: II. Métaphysique (Cómo yo veo, CV, 1948) (Teilhard de Chardin, Euvres, XI, 177-182 y 207-214), Teilhard mantiene su tesis básica del crecimiento del ser (plus esse) por la unión y, como consecuencia, la definición del ser a partir del unir. Además, Teilhard hace aquí un resumen breve, aunque completo (perspectiva física, teológica, metafísica y mística), de su metafísica de la unión en cuatro tiempos. Primer 
tiempo: se supone la presencia irreversible y autosuficiente de un Ser Primero (que podemos llamar, en paralelo al lenguaje de Teilhard, Punto Alfa), sin el cual no se puede fundamentar nada, que crea a partir de la nada. Segundo tiempo: para que este ser subsista sobre sí mismo en aislamiento es necesario verlo como diferenciándose a sí mismo trinitariamente (dato revelado). Tercer tiempo: Dios, por el hecho mismo de unificarse trinitariamente sobre sí mismo, hace surgir ipso facto una diferenciación en sus propias antípodas (y no en su corazón): la multiplicidad pura o nada física, también llamada nada verdadera o nada creable ${ }^{2}$ (que es una posibilidad o imploración de ser). (Sobre esta nada creable nos cuesta entender que sea ella la que solicite el ser y no sea el Dios libérrimo quien lo entrega.) Cuarto tiempo: El acto de creación del ser no es un gesto arbitrario de Dios, sino que aparece como una suerte de réplica o de simetría a la trinitización con tres consecuencias: (a) el acto de la Creación (a pesar de sus fases) no puede efectuarse más que una sola vez en la vida de Dios ${ }^{3}$; (b) para crear,

2 Para Teilhard, lo múltiple representa físicamente la nada verdadera, y la nada afirmada metafísicamente por la doctrina ex nihilo es para él pura abstracción. Así lo dejó escrito Teilhard en el ensayo "La lucha contra lo múltiple" (1917), preludio de L'Union créatrice: "Les éléments de la Terre, quels qu'ils soient, perdent leurs qualités et cessent d'exister pour nous, par réduction progressive de leur masse. L'être s'annule à force de se disperser. Il s'évanouit en pluralité (...) L'étoffe des choses deviendrait comme si elle n'était pas! Dissoute dans la non-activité et la non-réaction (...) elle serait indiscernable du Néant, équivalente, et donc identique au Néant. Si bien que, seul, le regard du Créateur pourrait la suivre (...) comme une aptitude infiniment diffuse à se resserrer, à se condenser, à se grouper (...) Anéantir le Monde physiquement, ce serait le réduire en poussière". Este ensayo se encuentra en Teilhard de Chardin, Euvres, XII, 131-132: "Los elementos de la tierra, cualesquiera que sean, pierden sus cualidades y dejaran de existir para nosotros por reducción gradual de su masa. El ser se anula a fuerza de dispersarse. Se desvanece en pluralidad (...) La urdimbre de las cosas sería como si no existiera! Disuelto en la inactividad y la no reacción (...) sería indistinguible de la nada, equivalente y, por tanto, idéntico a la nada. De modo que sólo la mirada del Creador lo podría seguir (...) como una potencia infinitamente difusa de contraerse, de condensarse, de agruparse físicamente (...) Destruir el mundo físicamente, sería reducirlo a polvo”. Sin embargo, esto no concuerda con nuestra concepción física actual en que la energía de ligadura es negativa y, por consiguiente, la dispersión aumenta la masa y la masa-energía total se conserva.

3 Aquí nos cuesta ver la fuerza del argumento que utiliza Teilhard entre esa trinitización única y esa creación única posible, porque en la visión cristiana la trinitización se realiza a través de las dos procesiones eternas: del Hijo y del Espíritu Santo, que en la visión católica hemos de ver como originadas del Padre, y del Padre y del Hijo, respectivamente. 
Dios se va sumergiendo en lo múltiple a fin de incorporárselo; (c) por tanto, para Dios atacar lo múltiple equivale necesariamente a luchar contra el mal (sombra de la creación). Así lo expone Teilhard:

En la metafísica clásica, lo usual ha sido siempre deducir el mundo a partir de la noción de ser, considerada, irreductiblemente, como primitiva. Apoyándome en las últimas investigaciones de la Física, que acaban de probar (a la inversa de la evidencia vulgar subyacente a toda philosophia perennis) que el movimiento no es independiente del móvil, sino que, al contrario, el móvil es físicamente engendrado (o más exactamente, co-engendrado) por el movimiento que le anima, voy a tratar de mostrar aquí que es posible una dialéctica más resistente y rica que las otras si se plantea como punto de partida que el ser, lejos de representar una noción terminal y solitaria, es en realidad definible (al menos genéticamente, si no ontológicamente) por un movimiento particular indisolublemente asociado a él, el de unión (Teilhard de Chardin, Euvres, XI, 207-208).

No obstante, Teilhard acaba matizando su postura contra la metafísica escolástica, al poner de manifiesto la complementariedad de las dos nociones, ser y unión. Estas dos nociones dice que son ontológicamente inseparables. Pero, en la idea de la unión creadora, el punto delicado está en poner en el origen de la creación una desunión absoluta, que parece una nada positiva, una potencial sombra de Dios. Así, correlativo a la existencia de Dios estaría el vacío. Teilhard describe este vacío como una multiplicidad infinita con la posibilidad de llegar a ser unida. De este modo, se afirma que hay necesariamente una multiplicidad infinita previa a cualquier acto creativo. Esto parece cuestionar la creatio ex nihilo. Pero, con esto Teilhard no niega la creación a partir de la nada, sino que está imaginando la nada como una multiplicidad infinita.

Así que, si para Plotino, la materia ocupa el último grado de la jerarquía como multiplicidad sin unidad, sin absolutamente ninguna forma, no-ser que no es todavía absolutamente nada, y por tanto, lo múltiple es punto final; para Teilhard, al contrario, lo múltiple es punto de partida. Plotino veía la materia como una degradación del Uno hacia lo múltiple. En cambio, Teilhard defiende una unión de lo múltiple, por tanto de la materia, hacia 
lo uno. La evolución es, así, para él una serie de síntesis progresivas. Estas síntesis representan las formas sucesivas de lo vivo, desde la más elemental hasta la más compleja, que es el ser humano, caracterizado por el espíritu (Martelet 2006, 28-29).

De hecho, Teilhard dice en su Diario del dia 20 de septiembre de 1917: "Es ciertamente curioso que el paso ex nihilo subjecti se haga bajo la forma de la aparición de la creatura en su mínimo de existencia, de perfección" (Teilhard de Chardin 1975, 219). Y en el capítulo tercero de UC dice algo similar: "La productio ex nihilo subjecti ha consistido, no en plantar con todas sus piezas un ser infinitesimal... destinado a crecer (...), sino en invertir aquella capacidad de dispersión” (Teilhard de Chardin 1965, 185). En efecto, Teilhard, al final del primer capítulo de UC, reconoce que existen separaciones en los phylum, que producen una dispersión de los elementos, pero defiende que esto es secundario y superficial, y nunca podrá llegar a producir una evolución divergente, pues los elementos del espíritu se orientan hacia un único centro de convergencia (Teilhard de Chardin 1965, 180). De este centro de convergencia sale la fuerza que crea el mundo, que no puede ser más que una atracción. La naturaleza de esta atracción es un centro unificador real y trascendente: Dios. Según Teilhard, esto solo puede ser así porque solo una energía unificante de origen extra-cósmico puede producir la agrupación de las mónadas, ya que lo múltiple es incapaz de agruparse ni de progresar por sí mismo en el ser, porque no puede producir más que dispersión (Teilhard de Chardin 1965, 181).

En defensa de Teilhard, de Lubac hace una aclaración matizadora de la posición de Teilhard de Chardin respecto a la creatio ex nihilo, al decir:

El mundo, tomado como un todo, es por lo tanto creado ex nihilo subjecti, en el sentido estricto de la palabra. Antes del acto creador no podemos decir que había algo intangible. (...) La multiplicidad pura ha de ser más bien concebida como un puro poder de dispersión que la creación consistiría en invertir (de Lubac 1962, 284).

Pero, por mucho que de Lubac intenta salvar la idea de la multiplicidad pura creable de Teilhard, ésta no es compatible con una creación ex nihilo, 
y por lo tanto, la idea de creación no puede consistir en invertir esa tendencia antagonista de Dios, que presenta Teilhard.

Así que la idea filosófica central de creatio ex nihilo no es compatible con esa multiplicidad pura eterna, que presenta Teilhard, independiente de una decisión libérrima de Dios, pues ello llevaría a concebir la creación como algo necesario, e incluso como un devenir de Dios. Además, el Papa Francisco dirigiéndose el pasado año a la Academia Pontificia de las Ciencias decía que para que haya evolución, primero ha de haber algo creado que evolucione: "La evolución de la naturaleza no se contrapone a la noción de creación, porque la evolución presupone la creación de los seres que evolucionan” (Francisco 2014).

En la perspectiva teilhardiana, la vida y la conciencia ya no aparecen como meros fenómenos accidentales o misteriosos en el universo, sino como la intensificación de una propiedad latente en toda materia (Teilhard de Chardin, Euvres, VIII, 27). Así que, ello implica que la materia totalmente pura (como la materia prima tomista) no existe actualmente, sino que todos los elementos del universo contienen algún germen de interioridad -la conciencia, según Teilhard- a pesar del hecho de que en los numerosos corpúsculos muy simples esta propiedad es imperceptible.

Dentro de la historia evolutiva del mundo, para la metafísica clásica, el papel de Dios Creador es ser la causa primera, el origen permanente de todo. Así, Teilhard dice -casi repitiendo la frase de Frederick Temple (1884, lect. 4) ${ }^{4}$-que "Dios, no tanto hace las cosas, cuanto hace que ellas se hagan" (Teilhard de Chardin, Euvres, III, 39). De este modo, el Creador respeta enteramente el dinamismo de la naturaleza y permite dar, a nivel fenoménico, una explicación a las relaciones entre los seres.

Según Teilhard, pues, la evolución es la expresión de la creación continua de Dios por la que Él unifica más y más el mundo. Por lo tanto, de acuerdo con la idea tomista de creatio continua, la Creación nunca ha cesado. De Lubac glosa así el pensamiento de Teilhard:

4 Frederick Temple (1821-1902) fue arzobispo de Canterbury en el s.XIX, quien en el ciclo de Conferencias de Bampton, en 1884, dijo la frase: "He [God] did not make the things, we may say; no, but He made them make themselves". 
Esto [un aumento de unión] es lo que representa cada ser particular, que aparece en el curso de la evolución del mundo, es decir, en el curso de la creación, que no cesa de continuar a lo largo del tiempo, como resultado de la unión de un cierto número de elementos que son, respecto a ella, una especie de nada relativa, puesto que son todavía multitud no condensada, no organizada, no unificada. $\mathrm{O}$ es mejor decir que este nuevo ser, en la novedad de la síntesis que le hace ser, resulta, no de esos elementos sino del acto que le hace surgir a partir de ellos (de Lubac 1962, 283).

No obstante, en una nota a pie de página en el tercer capítulo de UC, Teilhard parece diferenciar dos tipos de creación: "Habría así, de alguna manera, dos acciones creadoras divinas: la primera, cuasi-orgánica, que desembocaría en la aparición de la Multiplicidad pura (=efecto antagonista de la Unicidad divina). La segunda, cuasi-eficiente, que unificaría lo Múltiple (=creación propiamente dicha)" (Teilhard de Chardin 1965, 186, nota 10).

Sin embargo, hoy vemos la Creación como un solo acto, uno en la eternidad de Dios, pero que se despliega en el tiempo, y por tanto, constituye un proceso para el mundo. A pesar de esta diferenciación de la creación, para Teilhard, está claro que el acto creador de Dios no es un proceso, sino un acto indivisible. De ahí, que diga lo siguiente:

Se trata de una unión creadora, y la expresión vale tanto para cada nuevo individuo que aparece en el desarrollo del mundo, como para ese desarrollo en sí mismo, que en realidad es sobre todo una convergencia. (...) A la vez que por una unión, y por el hecho de esta unión, la intervención de la Causa primera se traduce... en una transformación: La «transformación creadora». (...) Esta unión, esta transformación con un acto verdaderamente creador y que sin embargo se apoya en un sujeto. El acto es en sí mismo co-extensivo con toda la duración del universo (de Lubac 1962, 286).

Con su visión poético-filosófica de la Creación, Teilhard entiende la manifestación empírica de la creación, a través de una modalidad evolutiva. Así, para él, la evolución es la modalidad empírica de la Creación. La creación así entendida, conlleva, pues, los efectos de una multiplicidad en constante evolución. Esto permite comprender el carácter incompleto de la creación: 
Al principio, pues, estaban los dos polos del ser, Dios y lo Múltiple [Ormuz y Ahrimán ${ }^{5}$. Y, sin embargo, Dios estaba bien solo, puesto que lo Múltiple soberanamente disociado no existe en él. (...) el ser recién nacido emergió de las profundidades de la pluralidad. Y su figura está todavía toda ahogada por la multiplicidad (Teilhard de Chardin, Euvres, XII, 132).

Así que según Teilhard, lo múltiple está en el punto de partida empírico del acto creador, y el Uno o el Espíritu es el término de la evolución. Teilhard afirma que, en virtud del mecanismo de la evolución, dentro del ciclo de la creación, "lo uno nace sobre lo múltiple, lo simple se forma uniendo lo complejo, el espíritu se hace por medio de la materia. De manera que, complejidad orgánica y simplicidad psíquica no se oponen, en el devenir: una de ellas, en efecto, es la condición de la aparición de la otra" (Teilhard de Chardin 1965 , 179). Teilhard describe así no el origen del alma en su pura trascendencia, sino el fenómeno de su aparición empírica, según el desarrollo de la evolución, que parte de la materia para ir hasta la aparición del espíritu (Martelet 2005, 70 y 72-73).

\section{El emergentismo evolutivo de Teilhard. La transiencia}

Como apuntábamos en el primer apartado, la teoría de la unión creadora (union créatrice) de Teilhard difiere de la evolución creadora (évolution créatrice) de Bergson, y se aproxima más a un tipo de creación evolutiva. De hecho, podemos decir que Teilhard lo sugirió: "E incluso, mucho mejor, una creación de tipo evolutivo” (Teilhard de Chardin, Euvres, III, 95). Es más, pensamos que Teilhard escribió L’union créatrice como réplica a la idea de la evolución creadora de Bergson, puesto que según Teilhard, la evolución misma no es creadora, sino que es la expresión de la actividad creadora de Dios. Nótese lo que escribe Teilhard en UC:

5 Ormuz y Ahrimán son las formas persas modernas de Ahura Mazda y Angra Mainyu, el dios y el anti-dios eternos, respectivamente, de la religión avéstica o zoroástrica de los antiguos persas, las cosmogonías que justamente el libro del Génesis excluye. 
Mientras que, en la Evolución creadora de Bergson, el Cosmos se revela como una irradiación divergente a partir de un manantial central, la figura del Universo, tal como la descubre la Union creadora, es la de una reducción, la de una convergencia, la de una confluencia centrípeta a partir de alguna esfera infinitamente distendida. Igualmente evolutivas, las dos teorías son inversas la una de la otra (Teilhard de Chardin 1965, 179).

De acuerdo con Teilhard, una evolución regular sería aquella en la que cada grado superior de ser nacería de la cooperación y agrupamiento de todas las fuerzas inferiores. Tal evolución sería infalible, absoluta y revelaría una verdadera inmanencia. En este sentido, Núñez de Castro (2008a, 114) hace notar que la actual teoría de la aparición de los organismos eucariotas confirma, en cierto sentido, la hipótesis de Teilhard de que el origen de los organismos eucariotas es resultado de una simbiosis de organismos procariotas, tesis que defendía con éxito Lynn Margulis (2002).

Además, Teilhard dice en el capítulo primero de UC que "la evolución universal tiene un sentido absoluto, el cual se dirige hacia el Espíritu" (Teilhard de Chardin 1965, 176), y que "el crecimiento del ser... representa la aparición, en el Mundo, de algo completamente nuevo" (Teilhard de Chardin 1965, 178). De ahí que Teilhard en su comprensión de la evolución del universo asume tres ideas básicas:

(a) En vez de una dualidad de espíritu y materia, aboga por solo un mundo, material pero con dos caras: una material, fuera («le dehors des choses») y otra psíquica o espiritual, dentro («le dedans des choses»).

(b) La evolución de tal mundo material significa un incremento en complejidad y conciencia.

(c) Tal incremento es causado por el hecho de que la Tierra, como esfera, tiene una superficie finita. Esto que dice Teilhard, en efecto, obliga a aumentar la densidad de los entes, pero no está claro que esto implique un aumento de complejidad, que viene más bien por conexiones internas.

Por otro lado, Teilhard se plantea qué fuerza crea ese devenir progresivo hacia el espíritu. Esa fuerza debe ser real y trascendente, porque la multi- 
plicidad pura no tiene en sí misma el principio de su unificación, por tanto esa fuerza debe ser trascendente y real, y atraer verdaderamente a la multiplicidad a que se una. En una concepción así, no se parte del ser como dado, sino como formándose progresivamente a través de la unión, como hace él.

La elevación de la conciencia y del espíritu implica la unión más estrecha de varios elementos. En Mi Universo (Teilhard de Chardin, Euvres, IX, 63-81) se introduce una novedad importante en la comprensión de la unión, y es la distinción entre la forma activa y la forma pasiva de unir, siendo la primera propia del alma, y la segunda de los elementos del cuerpo unidos por el alma: «Plus esse est plus cum pluribus uniri» (forma pasiva: ser más es estar más unido con varios elementos); «Plus esse est plus plura unire» (forma activa: ser más es unir más a varios elementos). Esto significa que recibir o comunicar la unión es sufrir la influencia creadora de Dios qui creat uniendo. El ser progresa, pues, en, y hacia, una unificación futura (unión creadora).

Asimismo, durante ese progreso hacia esa unificación se plantea la interacción o comunicabilidad de los seres entre sí, que Teilhard llama la transiencia. Esto para él no es un problema, porque, como dice en el capítulo quinto de UC, "cada cosa no subsiste, no se sostiene, sino por su confluencia con las otras" (Teilhard de Chardin, Euvres, XII, 213). Según Teilhard lo que cimenta la comunicabilidad de las mónadas ${ }^{6}$ no es el cuerpo (o la materia) sino el alma (o el espíritu). Lo que sostiene esa unión o transiencia de las mónadas es una cohesión en el futuro producida en el espíritu.

La transiencia de los seres (ser más = estar más unido; plus esse $=$ plus uniri) deviene una realidad fundamental a medida que el universo se desmaterializa. La transiencia es el esbozo de una inmanencia que se forma.

6 El término "mónada" lo toma Teilhard de la filosofía de Leibniz. Para Teilhard, "mónada" significa la individualidad humana en tanto que elemento de un todo. A diferencia de la mónada leibniziana, la mónada teilhardiana no es cerrada, sino que se encuentra abierta al cosmos y al otro, y está regida por la libertad y no por una armonía preestablecida. Las mónadas teilhardianas no son estáticas e independientes, sino solidarias tangencialmente (por su existencia y disposición respecto a las otras), radialmente entre ellas y radialmente con el Punto Omega. Estas mónadas tienen una parte igual en todas hacia la cual tienden (Punto Omega), que no es la unidad inicial de la que se separaron, y una parte propia. 
Así pues, la materia pierde todas sus cualidades de consistencia y de vinculación universal, pues según Teilhard, "la materia no es un principio de contacto, sino de separación” (Teilhard de Chardin 1965, 192). De hecho, puede verse aquí una reminiscencia del principio tomista de individuación, que considera la materia signata quantitate.

Cabe entender que esa inmanencia de la que habla Teilhard no es física sino metafísica, es decir, no se alcanza de forma natural. Así, dice él: "Entiendo por Cristo Universal el Cristo centro orgánico del universo entero: centro orgánico, es decir, del cual, en definitiva, está suspendido físicamente todo desarrollo, incluso el natural, del universo entero" (Teilhard de Chardin, Euvres, IX, 39).

\section{Materia y Espíritu}

El espíritu y la materia representan, para Teilhard, la doble vertiente inseparable de una sola y misma realidad. Según Teilhard, materia y espíritu no son otra cosa que distintas configuraciones del único ser creado, y entre ambos hay una continuidad ontológica perfecta. Así lo explica Martelet: “El Espíritu que se menciona aquí es el espíritu humano considerado genéticamente, es decir, tal que la materia en su evolución permite comprender la aparición gradual en su aspecto fenoménico" (Martelet 2005, 181-182). Por eso, Teilhard habla de «potencia espiritual de la materia» y veía en ella la «fuente armoniosa de las almas». Para todas las cosas, también para el espíritu, la materia es la matriz, la madre. De ahí que Teilhard diga: "el espíritu se hace por medio de la materia” (Teilhard de Chardin, Euvres, XII, 202). De hecho, de Lubac cita al filósofo belga Joseph Maréchal en apoyo de Teilhard: “Maréchal lo ha traducido diciendo: el alma espiritual es creada solo in corpore y opera con la ayuda de la materia” (de Lubac 1962, 287). Además, de Lubac arguye que esto está de acuerdo con la filosofía de Santo Tomás de Aquino, pues lo trata claramente en el artículo 10 de la cuestión 3 de De Potentia Dei: "El alma no tiene la perfección de su naturaleza fuera del cuerpo, ya que no es por sí misma la especie completa de una naturaleza, sino que es una parte de la naturaleza humana; en caso contrario sería preciso que el alma 
y el cuerpo no llegaran a ser una sola cosa más que por accidente. Por ello, el alma humana no fue creada fuera del cuerpo" (Tomás de Aquino, 1953).

El alma es el principio de unión que envuelve un agregado de unidades antiguas y acaba por formar una sustancia nueva. Así, "la unión ontológica... es propiamente creadora. La creación se realiza al unir; y la unión verdadera no se obtiene más que al crear" (Teilhard de Chardin 1965, 178). De ahí que Teilhard dirá que el alma humana, "principio de unidad del ser humano, sólo puede aparecer en el ejercicio de un acto de unión” (de Lubac 1962, 287).

Así, según Teilhard, no existen concretamente la materia y el espíritu, sino que existe solamente una materia que se hace espíritu. Ninguna otra sustancia podría producir el alma, sino el espíritu emergente de la materia. El alma, pues, que surge de la materia, por evolución, va siguiendo un telos, una dirección final, que llega al alma humana y tiende, a la vez, hacia el Punto Omega, proceso denominado cristificación. Así es como el proceso de cosmogénesis tiende hacia la espiritualización, hasta la deificación. Por tanto, podemos decir de acuerdo con Teilhard que el proceso de cosmogénesis se da por centrogénesis.

Aunque esa afirmación parece arriesgada, filósofos como Maréchal y teólogos como Smulders o de Lubac defendieron la inteligencia y la ortodoxia de Teilhard. Por ejemplo, de Lubac publica una carta de Joseph Maréchal sobre Teilhard de Chardin en la que dice sobre la cuestión del alma lo siguiente:

A pesar de su interioridad y su espontaneidad, la conciencia, en el hombre, está ligada por un vínculo natural, a la materia organizada: nuestra conciencia no es la de los espíritus puros. En consonancia con el resto de la materia (aunque no en total dependencia de ella), el hombre ocupa por derecho propio un lugar en las series cronológicas y las secuencias teóricas de la historia natural: hay un fenómeno humano, y entre los fenómenos no se puede pensar una discontinuidad total. [Pretende así,] Hacer una teoría empírica del hombre, considerado en su continuidad con el resto de la naturaleza, pero sin la pretensión de explicar por esta continuidad todo sobre el hombre; al revés, interpretar la naturaleza misma, en su movimiento ascendente hacia el hombre, por las analogías, que nos sugiere la percepción inmediata y todo el interior de nuestra vida conscien- 
te; identificar el alcance de la correlación humana entre el mundo interior de la conciencia y el mundo exterior de la materia (de Lubac 1962, 362).

También Smulders hace un juicio sobre Teilhard análogo al de Maréchal:

Esta concepción, que hace especial hincapié en la afinidad entre el hombre y el mundo material parece suficiente para salvaguardar los dogmas de la espiritualidad y la creación del alma humana. No contento con la definición actual, que define lo espiritual de una manera negativa como lo no-material, caracteriza el alma humana como un grado de interiorización que no es otro que la reditio completa ad seipsum tomista. Y haciendo hincapié en el valor de ser único y absoluto de todos los hombres, la concepción teilhardiana no sólo deja lugar para la doctrina de la creación del alma, sino que la implica. Al producir el hombre, la evolución produce un ser que es más que un eslabón en la cadena evolutiva, pues por su valor absoluto se encuentra en relación inmediata con su Creador (de Lubac 1962, 363).

Además, el propio Joseph Ratzinger también señaló, con matices, que Teilhard había logrado expresar bien la alternativa entre materialismo y espiritualismo, entre casualidad y sentido:

¿entendemos el espíritu y la vida en sus formas ascendentes tan sólo como un moho casual sobre la superfície de lo material (es decir, del ser que no se comprende a sí mismo), o como la meta de todo el proceso, y en consecuencia consideramos a la materia como la prehistoria del espíritu? Si nos decidimos por lo segundo, queda claro que el espíritu no es un producto casual de la evolución material, sino más bien la materia tiene el papel de ser un momento en la historia del espíritu. Y esto no es más que otra forma de expresar el hecho de que el espíritu ha sido creado y no es mero producto del desarrollo, aunque aparezca bajo la forma de evolución (Ratzinger 1973, 158-159).

Y un poco más adelante, haciendo referencia a la creación especial del alma humana, sigue Ratzinger:

Luego habría que hablar de que el espíritu no es algo extraño, añadido, una segunda substancia que se une a la materia; la aparición del espíritu, según lo que hemos dicho, significa más bien que un movimiento progresivo llega a la 
meta que se le ha señalado. Finalmente, habría que decir que si hay algo que no podemos representarnos como una actividad artesanal por parte de Dios es la creación del espíritu. Si creación es equivalente a dependencia del ser, creación especial es dependencia especial. La consideración de que el hombre ha sido creado por Dios de una manera más específica y más directa que el resto de las cosas significa, expresado de una forma menos plástica, simplemente que el hombre ha sido querido por Dios de una manera especial: no solamente como un ser que existe, sino como un ser que le conoce; no solo como figura en la que él ha pensado, sino como existencia que puede a su vez pensar en él. A esta manera especial del ser conocido y querido el hombre por parte de Dios la llamamos nosotros creación especial (Ratzinger 1973, 159-160).

El alma humana ha sido querida especialmente por Dios. El Creador no la ha lanzado un buen día en un mundo artificialmente preparado para recibirla, sino que, para Teilhard, la ha hecho nacer una primera vez, y continúa cada día haciéndola nacer, por una acción maravillosamente mezclada, desde siempre, a la evolución del universo. Hoy día solemos concebir la acción creadora divina como potenciadora en los homínidos o fetos humanos, que soporta creadoramente esa emergencia, en el caso eminentemente singular de la hominización.

En efecto, existe un orden en la multiplicidad de las cosas, desde lo sencillo a lo complejo. La materia organizada tiende a ser multiplicada y diferenciada infinitamente, formando el árbol de la vida. Pero, esta disposición ordenada de complejidad no es estática, sino dinámica y está movida por un flujo de interiorización, que va de menos interioridad o conciencia a más conciencia o alma, desde la zona pre-viviente hasta la zona del pensamiento, respectivamente. Ciertamente, hay varios grados de complejidad de conciencia, pero difícilmente podemos concebir su presencia en elementos pre-bióticos e, incluso, partículas subatómicas.

Según Teilhard, el aumento de complejidad conduce a una clasificación natural, una secuencia de la emergencia de corpúsculos de mayor complejidad. Los grados de complejidad corresponden a un orden histórico: las formas más complejas solo llegan a existir cuando las formas de menor complejidad ya existen durante un largo tiempo. De ahí que en la totalidad de 
las series moleculares, a nivel de la química orgánica, el número de átomos asociados en cada partícula alcanza rápidamente números astronómicos. Así que, vemos cómo una estructura cada vez más rica y mejor organizada corresponde a una conciencia más desarrollada. Pero, cuando se cruza el umbral de la biosfera, la complejidad -claramente dinámica- aumenta en progresión geométrica, por ejemplo, al pasar del protozoo hacia más y más arriba en la escala de los metazoos (Teilhard de Chardin, EEuvres, I, 56-57).

Sin embargo, la materia evoluciona, no solo hacia la conciencia de sí misma (el espíritu), sino principalmente hacia la posesión de sí misma (la persona) y la donación de sí misma (el amor personal). Luego, la evolución es el paso desde una menor centro-complejidad a otra mayor. Así que el alma humana surge en la noosfera, como evolución desde una menor complejidad de interiorización (o centro-complejidad) a otra mayor. La máxima centro-complejidad será el alma humana perfecta, que como dice Teilhard en el primer capítulo de UC, "es incorruptible. Y, sin embargo, sigue siendo solidaria de la Multitud que sigue prolongándose, genética y virtualmente, en ella” (Teilhard de Chardin 1965, 178-179). De este modo, para Teilhard, se hace visible el mecanismo de la espiritualización por unión. De hecho, en el capítulo cuarto de UC, la teoría de la unión creadora establece una relación directa entre la espiritualidad del alma y la complejidad del cuerpo. El ser creado es tanto más espiritual cuanto más grande fuera su multiplicidad inicial (Teilhard de Chardin 1965, 187).

Llegado al punto final de la evolución cósmica, que Teilhard llama Punto Omega, el alma se identifica con el ser humano más perfecto, con la máxima interioridad, es decir, Aquél que es y está en la máxima intimidad con Dios: Cristo.

\section{El carácter divino de la evolución teilhardiana}

Como observa Cacho (2008, 86-92), Teilhard ofrece en Le milieu divin (Teilhard de Chardin, Euvres, IV) una visión teísta que está de acuerdo con la visión evolucionista del mundo. Allí propone un silogismo evolucionista, al estilo aristotélico que reza así: 
En el seno del universo, toda alma es para Dios.

Por otra parte, toda la realidad, incluso la material... es para nuestra alma.

Luego, toda la realidad sensible es, por nuestra alma, para Dios (Teilhard de Chardin, Euvres, IV, 41-42).

La proposición mayor «En el seno del universo, toda alma es para Dios», considerada el alma separada del cuerpo, sería la traducción clásica de una verdad de fe: «el alma es para Dios». Así, la naturaleza de esta unión alma-Dios debe ser intrínseca.

En la proposición menor del silogismo, Teilhard afirma que «la materia es para el alma». Nótese que un fin todavía inexistente (el alma, que es espiritual) moviliza y atrae el medio ya existente (la materia), y con la particularidad de que este medio es cualitativamente inferior al fin. El espíritu humano emerge, pues, de innombrables energías del mundo material.

La lógica del silogismo teilhardiano precisa deducir la conclusión de las dos proposiciones enunciadas: «Luego, en el seno del universo la materia es para Dios». Si al interior de un universo en evolución ascendente el espíritu converge en Dios y la materia converge en el espíritu, es razonable concluir que la materia converge en Dios, el Dios encarnado en el universo, el Cristo Cósmico. El Logos se encarna no solo en las zonas más elevadas del espíritu, sino también en los fondos más oscuros de la materia. Por eso, para Teilhard, la Encarnación no ha terminado:

Solo se habrá terminado cuando la porción de la substancia escogida que todo objeto incluye (...) se habrá reunido con el Centro definitivo de su compleción. (...) La creación... continúa progresando más y más, y en las zonas más elevadas del mundo. (...) A través de cada una de nuestras obras, trabajamos atómica pero realmente, en la construcción del Pléroma, es decir, que aportamos al Cristo un poquito de plenitud (Teilhard de Chardin, Euvres, IV, 49-50).

Dios crea evolutivamente, es decir, hace que vayan apareciendo evolutivamente los seres, tanto inanimados como animados, que pueblan el universo. Así, según Teilhard:

Mientras que, en el caso de un mundo estático, el Creador (causa eficiente) se encuentra -como sea- estructuralmente desligado de su obra y, por tanto, sin 
base clara para su inmanencia, en el caso de un mundo de naturaleza evolutiva, por el contrario, Dios ya no es concebible (ni estructural, ni dinámicamente) sino en la medida en que, como un tipo de causa formal coincida (sin confundirse) con el Centro de convergencia de la Cosmogénesis (Teilhard de Chardin, Euvres, X, 288).

Si desde Aristóteles la acción de Dios era concebida actuando a partir de los orígenes (a retro), a partir de la constatación del sentido evolutivo del universo en su totalidad, Teilhard defiende que solo es posible concebir un Dios que nos atrae hacia delante ( $a b$ ante).

Como sugiere Martelet (2006, 27-28), Teilhard quiere simplemente proponer un modelo que permita comprender cómo, para Dios, crear no es dar a la naturaleza algo que la distinga radicalmente de Él; sino al contrario, mostrar que este mundo viene a la existencia de acuerdo con su carácter de creatura, de ser creado. Con ello, Teilhard define las creaturas, en tanto que seres creados, como las que reciben su ser del Ser Absoluto, es decir, de Dios.

En efecto, para Teilhard, Cristo es el Punto Omega, que culmina la evolución del mundo, lo trasciende y diviniza. Por eso, el Logos es el Cristo Cósmico, que impulsa físicamente el origen de la evolución del cosmos. Es el principio físico de la evolución, que penetra realmente el proceso entero de la evolución del cosmos. En términos teilhardianos, podemos decir que «Cristo hace evolucionar la evolución». El Cristo Cósmico consuma físicamente el culmen de la evolución. Él es el vértice físico de la evolución.

Para Teilhard, pues, la imagen de Dios no podía ser otra que la del Dios de la evolución. Esta imagen tendrá, según él, dos vertientes: la del Dios evolucionador, principio animador de todo devenir del cosmos, y la del Dios evolutivo, que se transforma de alguna manera al crear. Por ello, Teilhard dirá que Dios solo actúa evolutivamente (Núñez de Castro 2008b, 106).

No obstante, la clave hermenéutica que puede proporcionar la última explicación del modelo del Dios evolutivo y evolucionador es, según Teilhard, el misterio trinitario de la revelación cristiana. Como observa Núñez de Castro (2008b, 117-118), si Dios no fuera trino, no podríamos concebir 
su existencia independiente de un mundo; si Dios no fuera trino, no podríamos concebir la Creación y, consiguientemente, la Encarnación.

El Dios-hacia-delante, principio animador y consumador del proceso evolutivo es un modelo de Dios mucho más comprensible para el hombre actual. Así pues, para Teilhard, Dios es el Dios de la evolución, el Dios que da sentido a la evolución del universo desde las primeras partículas hasta el ser humano; el Dios evolutivo y evolucionador, Principio y Fin, Alfa y Omega de todo el proceso evolutivo del cosmos; Dios trino, porque es comunión en el amor ( $\pi \varepsilon \rho \iota \chi \omega ́ \rho \sigma \iota \varsigma)$, en Él y con todos los seres inteligentes que ha creado.

El teólogo australiano Denis Edwards, gran estudioso de las obras de Rahner y Teilhard, sugiere que "el fundamento para una teología que se tome seriamente la evolución, se debe encontrar en una visión trinitaria de Dios, un Dios de relaciones mutuas, un Dios que es comunión en el amor” (Edwards 1999, 15). También el teólogo salesiano Franco Esparza (2002) ha propuesto la perspectiva trinitaria como paradigma más idóneo para una cosmovisión dinámica, que sugiere concebir la realidad en su totalidad, bajo el principio de la unión diferenciada.

\section{Conclusión}

En su weltanschauung, Teilhard distingue tres niveles de percepción: física o fenomenología, metafísica o hiper-física y mística. Pero, el objeto de percepción siempre es la realidad entera. En el contexto teilhardiano, física significa un tipo de fenomenología, una fenomenología del cosmos, de la vida y, particularmente, de la humanidad y su historia. Por tanto, las cuestiones relativas al futuro de la humanidad y del universo son parte de la física de Teilhard. La metafísica o hiper-física interpreta el proceso de evolución como un efecto de unificación, como un proceso de creación y un proceso de cristificación. Así, el concepto teilhardiano de evolución no se restringe a la evolución biológica, sino que incluye la historia del universo y la de la humanidad (Casadesús 2014, 373).

Por tanto, según Teilhard, el universo se encuentra en un estado de evolución cósmica de la que la evolución humana es una parte integral. 
Nuestro universo es, pues, un universo en convergencia hacia la unión con Dios, por el camino de un aumento continuo de conciencia. Detrás de esta concepción hay lo que Teilhard llama «el poder espiritual de la materia», que permite a la materia misma llegar a ser la matriz del espíritu; y a su vez, el espíritu, ser un estado superior de la materia (Casadesús 2014, 375).

Por eso, Teilhard apuesta por una metafísica del uniri en vez de una metafísica del esse. Es decir, en vez de tomar el ser como principio ontológico de toda la realidad, nuestro pensamiento se debe dirigir hacia otro principio ontológico: el converger de toda la realidad, concebida como proceso que llega a ser constantemente.

La llamada metafísica de la unión es una construcción dinámica y evolutiva del universo, que se sitúa entre una fenomenología del fenómeno humano y una mística. Como hemos advertido en este estudio, la metafísica de la unión no es un sistema ya acabado; al contrario, contiene limitaciones, errores e, incluso, aporías. Así pues, no hay definitividad en el esfuerzo enorme que Teilhard hizo por reformular la metafísica escolástica que él estudió, desde la visión cosmológica y física que la ciencia de su tiempo comenzaba a poner de manifiesto (Casadesús 2014, 378). En definitiva, pensamos que cabe intensificar más y mejor la búsqueda de una configuración integradora, a la vez que distintiva, entre metafísica y ciencia. El intento y esfuerzo que hizo Teilhard de Chardin creemos que es un acicate para ello.

\section{Referencias}

Barthélémy-Madaule, M. 1963. Bergson et Teilhard de Chardin. París: Seuil. Ratzinger, J. 1973. Dogma und Verkündigung. Munich: Erich Wewel Verlag. Bergson, H. 1907. L'évolution créatrice. París: PUF.

Cacho, I. 2008. "L'univers de Teilhard com a medi diví". En Actualitat de Teilhard de Chardin. M. García Doncel y J. M. Romero Baró (eds.), 59-100. Barcelona: Cruïlla \& Fundació Joan Maragall.

Casadesús, R. 2014. "L'évolution comme métaphysique de l'union chez Teilhard de Chardin”, Revue des Questions Scientifiques, 185: 373-398. 
De Lubac, H.-M. 1962. La pensée religieuse du Père Pierre Teilhard de Chardin. París: Aubier Montaigne.

Edwards, D. 1999. The God of Evolution. A Trinitarian Theology. New York: Paulist Press.

Francisco, 2014. Discurso a la sesión plenaria de la Academia Pontificia de las Ciencias, Ciudad del Vaticano, 27 de octubre de 2014.

Franco Esparza, J. A. 2002. Líneas de fuerza emergentes del pensamiento de Teilhard (II). http://www.redcientifica.com/doc/doc200212020331.html [consultada el 14 de octubre de 2011].

Margulis, L. 2002. Planeta simbiótico: Un nuevo punto de vista sobre la evolución. Madrid: Debate.

Martelet, G. 2005. Teilhard de Chardin prophète d'un Christ toujours plus grand. Primauté du Christ et transcendance de l'homme. Bruselas: Lessius.

Martelet, G. 2006. Et si Teilhard disait vrai... París: Parole et Silence.

Núñez de Castro, I. 2008a. “The Bio-Philosophy of Theilhard de Chardin”. God seen by Science: Anthropic evolution of the universe. En C. Heller Del Riego (ed.), 99-126. Madrid: Universidad Pontificia de Comillas.

Núñez de Castro, I. 2008b. “La nova imatge de Déu en Teilhard”. En Actualitat de Teilhard de Chardin, M. García Doncel y J. M. Romero Baró (eds.), 101-124. Barcelona: Cruilla \& Fundació Joan Maragall.

Tomás de Aquino, 1953. Quaestiones Disputatae de Potentia Dei, Textum Taurini.

Sequeiros, L. 2008. “Teilhard de Chardin i la gènesi del seu pensament”. En. Actualitat de Teilhard de Chardin. M. García Doncel y J. M. Romero Baró (eds.), 13-35. Barcelona: Cruilla \& Fundació Joan Maragall.

Teilhard de Chardin, M.-J. P. 1955-1976. EEuvres de Pierre Teilhard de Chardin, vols.I, III, IV, VIII-XIII. París: Le Seuil.

Teilhard de Chardin, M.-J. P. 1961. Genèse d'une pensée. Lettres 1914-1919. París: Bernard Grasset.

Teilhard de Chardin, M.-J. P. 1965. Écrits du temps de la guerre (1916-1919). París: Bernard Grasset.

Teilhard de Chardin, M.-J. P. 1974. Lettres intimes à Auguste Valensin, Bruno de Solages, Henri de Lubac (1919-1955). París: Aubier Montaigne.

Teilhard de Chardin, M.-J. P. 1975. Journal. 26 août 1915 - 4 janvier 1919. París: Fayard.

Temple, F. 1884. "Apparent conflict between religion and the doctrine of evolution". En The Relations Between Religion and Science, Bampton Lectures. 